\title{
Effects of the Microsomal and Soluble Fractions from Livers of Rats Poisoned with $\mathrm{CCl}_{4}$ on Mitochondrial Respiration
}

\author{
Tohoru HASEGAWA* and Masana OGATA \\ Department of Public Health, Okayama University Medical School, \\ Okayama 700, Japan \\ (*Present Address: Department of Community Health Science, Saga \\ Medical School, Nabeshima, Saga 840-01, Japan)
}

(Received April 12, 1982 and in revised form May 10, 1982)

\begin{abstract}
The microsomal fraction (pellet: $105,000 \times \mathrm{g}$ for $60 \mathrm{~min}$ ) from the livers of rats poisoned with $\mathrm{CCl}_{4}$ showed uncoupled normal mitochondrial oxidative phosphorylation in vitro. The supernatant fraction $(105,000 \times \mathrm{g}$ for $60 \mathrm{~min})$ antagonized the uncoupling action of the microsomal fraction and stimulated the respiratory control of mitochondria caused by central depression of state 4 respiration.
\end{abstract}

Keywords: Microsomal and soluble fraction-Mitochondria-Poisoning with $\mathrm{CCl}_{4}$.

\section{INTRODUCTION}

Carbon tetrachloride $\left(\mathrm{CCl}_{4}\right)$ is known to be a potent causative agent of hepatitis. Mitochondria from livers of animals poisoned with this compound are in the uncoupled state ${ }^{1,2)}$, with some lysosomal enzymes being released into the soluble fraciton ${ }^{3,4)}$. Previously, $\mathrm{CCl}_{4}$ was thought to attack mitochondria directly, leading to the uncoupled state ${ }^{1)}$. However, significant microsomal changes due to this poison precede mitochondrial dysfunction and parallel the appearance of fatty liver; hence the subcellular target of $\mathrm{CCl}_{4}$ is now thought to be the endoplasmic reticulum ${ }^{5)}$.

We observed that the microsomal fraction (pellet: $105,000 \mathrm{~g} \times 60 \mathrm{~min}$ ) from the livers of rats poisoned with $\mathrm{CCl}_{4}$ showed uncoupled normal mitochondrial oxidative phosphorylation in vitro. The supernatant fraction $(105,000 \mathrm{~g} \times 60 \mathrm{~min})$ antagonized the uncoupling action of the microsomal fraction and stimulated the respiratory control of mitochondria caused by central depression of state 4 respiration.

\section{Materials ANd Methods}

Male Donryu rats (weighing from 200 to $300 \mathrm{~g}$ ) fed on a laboratory stock 
diet were injected intraperitoneally with $\mathrm{CCl}_{4}(1.5 \mathrm{ml} / \mathrm{kg}$ of body weight $)$. They were killed by decapitation 48 and 120 hours after the injection. The liver was immediately immersed in ice-cold $0.25-\mathrm{M}$ sucrose containing $4 \mathrm{mM}$ Tris- $\mathrm{HCl}$ buffer ( $\mathrm{pH} 7.5$ ) and then fractionated by differential centrifugation ${ }^{6,7}$.

Respiration and oxidative phosphorylation was measured in a reaction mixture of $3.5 \mathrm{ml}$ containing $0.15 \mathrm{M} \mathrm{KCl}, 10 \mathrm{mM}$ Tris- $\mathrm{HCl}$ buffer ( $\mathrm{pH} 7.5$ ), $2.5 \mathrm{mM}$ potassium phosphate buffer ( $\mathrm{pH} 7.5$ ), $5 \mathrm{mM}$ sodium succinate and $0.3 \mathrm{mM}$ sodium ADP at $25^{\circ} \mathrm{C}$ with a galvanic oxygen electrode (Kyusui Kagaku Co. Ltd. Tokyo).

Protein concentration was measured by the biuret method with bovine serum albumin as the standard.

$\mathrm{CCl}_{4}$ was purchased from Wako Pure Chemical Industry Ltd. All other reagents used in this experiment were of reagent grade.

\section{RESUlts}

Isolated normal mitochondria showed the respiratory activity demonstrated in Table 1. State 3 respiratory activity was $116.2 \pm 7.2$ natoms of $\mathrm{O}_{2} / \mathrm{min} / \mathrm{mg}$ of protein, state 4 respiratory activity was $2.2 .3 \pm 1.9$ natoms of $\mathrm{O}_{2} / \mathrm{min} / \mathrm{mg}$ of protein and the respiratory control index (RCI) was $5.24 \pm 0.37$, suggesting that these mitochondria were tightly coupled.

When a $\mathrm{CCl}_{4}$-poisoned fraction (from the supernatant fraction $10,000 \mathrm{~g} \times 10$ $\mathrm{min}$ ) was added to the reaction mixture, state 4 respiration was markedly increased, from 22.3 to 34.7 natoms of $\mathrm{O}_{2} / \mathrm{min} / \mathrm{mg}$ of protein, and consequently the $\mathrm{RCI}$ decreased from 5.24 to 3.0 , suggesting that the mitochondria were uncoupled by the $\mathrm{CCl}_{4}$-poisoned fraction.

In contrast, when a normal fraction was added to the reaction mixture, almost no change in respiratory activity was observed, suggesting that the normal fraction did not possess the uncoupling activity.

Characterization of the uncoupling action

The uncoupling activity of the $\mathrm{CCl}_{4}$-poisoned fraction was not observed in a

Table 1. The effect of the supernatant fraction $(10,000 \mathrm{~g} \times 10 \mathrm{~min})$ from the livers of rats poisoned with $\mathrm{CCl}_{4}$ on mitochondrial respiration.

\begin{tabular}{lllc}
\hline & State 3 & State 4 & $\begin{array}{c}\text { RCI } \\
\text { (state 3/state 4) }\end{array}$ \\
\hline Control & $116.2 \pm 7.2$ & $22.3 \pm 1.9$ & $5.24 \pm 0.37^{*}$ \\
+ Normal fraction (3.4 mg of protein) & $115.0 \pm 6.8$ & $21.3 \pm 0.47$ & $5.4 \pm 0.43$ \\
$+\mathrm{CCl}_{4}$ fraction (3.6 mg of protein) & $109.0 \pm 5.2$ & $34.7 \pm 4.0$ & $3.0 \pm 0.29$ \\
+ boiled $\mathrm{CCl}_{4}$ fraction & $111.0 \pm 6.8$ & $21.3 \pm 2.6$ & $5.3 \pm 0.85$ \\
\hline
\end{tabular}

State 3 and state 4 respiration are expressed as natoms of $\mathrm{O}_{2} / \mathrm{min} / \mathrm{mg}$ of protein. $\mathrm{CCl}_{4}$ fration was prepared from the livers of $\mathrm{CCl}_{4}$-poisoned rats 2 days after injection.

$*($ mean + S.D. $n=6)$ 
boiled $\mathrm{CCl}_{4}$-poisoned fraction (Table 1). Bovine serum albumin did not inhibit the uncoupling. The change in the uncoupling activity of the $\mathrm{CCl}_{4}$-poisoned fraction with time was examined and the result is shown in Fig. 1. Uncoupling activity 2 days after the injection was greater than that 5 days after the injection.

The $\mathrm{CCl}_{4}$-poisoned fraction was centrifuged to separate the microsomal and soluble fractions. As shown in Table 2, the mainly microsomal fraction (pellet: $105,000 \times 60 \mathrm{~min})$ from $\mathrm{CCl}_{4}$-poisoned liver had uncoupling activity; a slight decrease in state 3 respiration from 116 to 110 natoms of $\mathrm{O}_{2} / \mathrm{min} / \mathrm{mg}$ of protein and an increase in state 4 respiration from 20.7 to 25.4 natoms of $\mathrm{O}_{2} / \mathrm{min} / \mathrm{mg}$ of protein occurred. The RCI decreased from 5.6 to 4.2 .

In contrast, a marked change was brought about by the $\mathrm{CCl}_{4}$-supernatant fraction ( $\mathrm{S}$ fraction: $105,000 \mathrm{~g} \times 60 \mathrm{~min}$ ). As shown in Table 2, the $\mathrm{CCl}_{4}-\mathrm{S}$ fraction decreased mainly state 4 respiratory activity from 20.7 to 16.0 natoms of $\mathrm{O}_{2} / \mathrm{min}$ / $\mathrm{mg}$ of protein and consequently increased the RCI from 5.6 to 7.0, suggesting

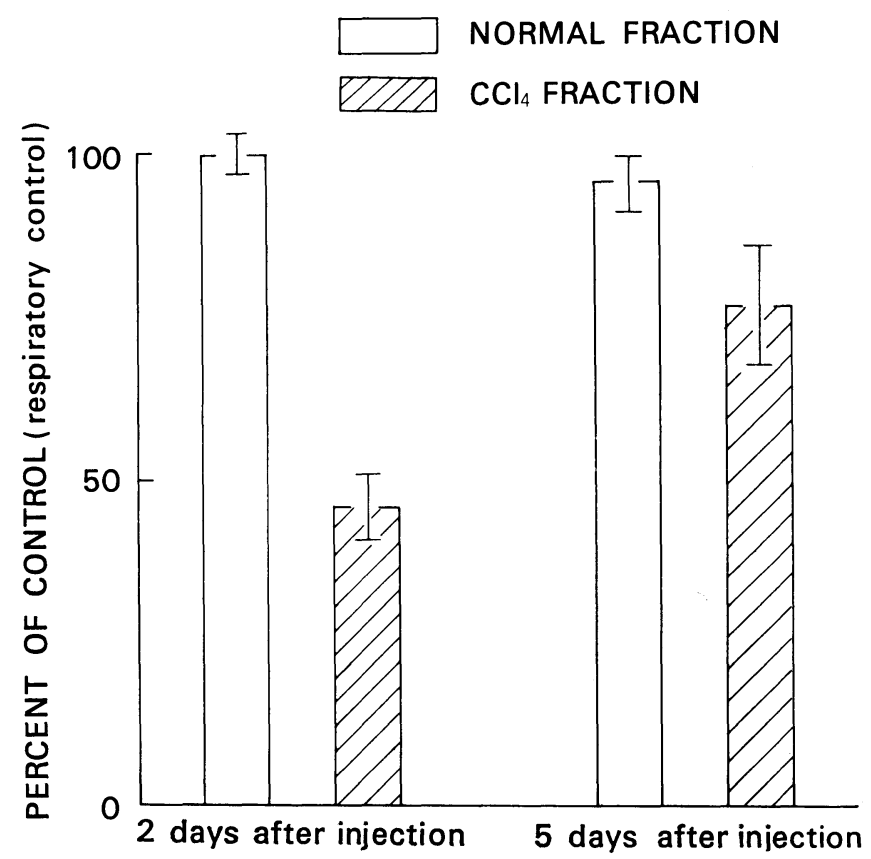

Fig. 1. The effect of the supernatant fraction $(10,000 \mathrm{~g} \times$ $10 \mathrm{~min}$ ) on the respiratory control of normal rat liver mitochondria.

The respiratory control index of normal rat liver mitochondria was $5.24 \pm 0.37$ and the concentration of mitochondrial protein was $3.2 \mathrm{mg} / \mathrm{ml}$. Protein concentration of the normal supernatant fraction and of the $\mathrm{CCl}_{4}$-supernatant fraction added to the reaction mixture was $2.0 \mathrm{mg}$. 
Table 2. The effects of the microsomal and soluble fractions from livers of rats poisoned with $\mathrm{CCl}_{4}$ on mitochondrial oxidative phosphorylation.

\begin{tabular}{llllc}
\hline & State 3 & \multicolumn{1}{c}{ State 4} & \multicolumn{1}{c}{ RCI } & \% of control \\
\hline Control & $116 \pm 8.0^{*}$ & $20.7 \pm 1.3$ & $5.6 \pm 0.04$ & 100 \\
+ Normal M (2.1 mg of Protein) & $115 \pm 2.2$ & $21.5 \pm 0.09$ & $5.4 \pm 0.08$ & 96 \\
$+\mathrm{CCl}_{4} \mathrm{M} \mathrm{(2.4} \mathrm{mg} \mathrm{of} \mathrm{protein)}$ & $110 \pm 5.9$ & $25.9 \pm 1.1$ & $4.2 \pm 0.2$ & 70 \\
$+\mathrm{Normal}^{\mathrm{S}}(1.2 \mathrm{mg}$ of protein) & $110 \pm 3.9$ & $21.6 \pm 0.8$ & $5.1 \pm 0.04$ & 89 \\
$+\mathrm{CCl}_{4} \mathrm{~S}$ (1.3 mg of protein) & $111 \pm 6.1$ & $16.0 \pm 1.2$ & $7.0 \pm 0.2$ & 130 \\
\hline
\end{tabular}

Normal $\mathrm{M}$ refers to the pellet fraction of $105,000 \mathrm{~g} \times 60 \mathrm{~min}$ centrifugation from normal liver. $\mathrm{CCl}_{4} \mathrm{M}$ refers to the pellet of $105,000 \mathrm{~g} \times 60 \mathrm{~min}$ centrifugation from livers of $\mathrm{CCl}_{4}$-poisoned rats 5 days after injection. Nomal $\mathbf{S}$ refers to the supernatant fraction of $105,000 \mathrm{~g} \times 60 \mathrm{~min}$ centrifugation from normal liver. $\mathrm{CCl}_{4} \mathrm{~S}$ refers to the supernatant fraction of $105,000 \mathrm{~g} \times 60 \mathrm{~min}$ centrifugation from livers of $\mathrm{CCl}_{4}$-poisoned rats 5 days after injection. State 3 and state 4 respiration are expressed as natoms of $\mathrm{O}_{2} / \mathrm{min} / \mathrm{mg}$ of protein.

* $($ mean \pm S.D. $n=6)$

Table 3. Characterization of the stimulatory activity of the supernatant fraction $(105,000 \mathrm{~g} \times 60 \mathrm{~min})$ from the livers of rats poisoned with $\mathrm{CCl}_{4}$ for respiratory control of mitochondria.

\begin{tabular}{llccl}
\hline & State 3 & State 4 & \multicolumn{1}{c}{ RCI } \\
\hline $\mathrm{A}:$ & Control & 116 & 20.7 & 5.6 \\
& $+\mathrm{CCl}_{4} \mathrm{M}$ fraction & 110 & 24.8 & $4.43^{*}$ \\
& $+\mathrm{CCl}_{4} \mathrm{M}$ fraction + normal S & 118 & 25.1 & $4.7 * *$ \\
& $+\mathrm{CCl}_{4} \mathrm{M} \mathrm{fraction}+\mathrm{CCl}_{4} \mathrm{~S}$ & 120 & 17.9 & $6.7 * * *$ \\
\hline $\mathrm{B:}$ & $+\mathrm{Normal} \mathrm{S}$ & 108 & 21.5 & 5.0 \\
& $+\mathrm{CCl}_{4} \mathrm{~S}$ & 104 & 14.4 & 7.25 \\
& + boiled normal S & 124 & 23.3 & 5.31 \\
& + boiled $\mathrm{CCl}_{4} \mathrm{~S}$ & 113 & 21.5 & 5.25 \\
\hline
\end{tabular}

State 3 and state 4 respiration are expressed as natoms of $\mathrm{O}_{2} / \mathrm{min} / \mathrm{mg}$ of protein. $\mathrm{CCl}_{4} \mathrm{M}$ fraction refers to the microsomal fraction from the livers of $\mathrm{CCl}_{4}$-poisoned rats 5 days after injection. Normal $S$ refers to the supernatant fraction of $105,000 \mathrm{~g}$ $\times 60 \mathrm{~min}$ centrifugation from normal liver and $\mathrm{CCl}_{4} \mathrm{~S}$ refers to the supernatant fraction of $105,000 \mathrm{~g} \times 60 \mathrm{~min}$ centrifugation from the livers of $\mathrm{CCl}_{4}$-poisoned rats 5 days after injection.

$*\left(\mathrm{CCl}_{4} \mathrm{M}\right.$ fraction: $0.5 \mathrm{mg}$ of protein) ** (Normal $\mathrm{S}: 1.2 \mathrm{mg}$ of protein)

$* * *\left(\mathrm{CCl}_{4} \mathrm{~S}: 1.3 \mathrm{mg}\right.$ of protein)

that a more tightly coupled state of oxidative phosphorylation is brought about by the $\mathrm{CCl}_{4}-\mathrm{S}$ fraction.

\section{Characterization of the stimulatory activity of the $\mathrm{CCl}_{4}-\mathrm{S}$ fraction}

The stimulatory activity of the $\mathrm{CCl}_{4}-\mathrm{S}$ fraction for respiratory control was heat labile (Table 3 ) and antagonized the uncoupling action of the microsomal fraction (Table 3 ). The effect of concentration on the stimulatory activity was measured, with the results shown in Fig. 2 . The $\mathrm{CCl}_{4}-\mathrm{S}$ fraction prepared 5 days after the 


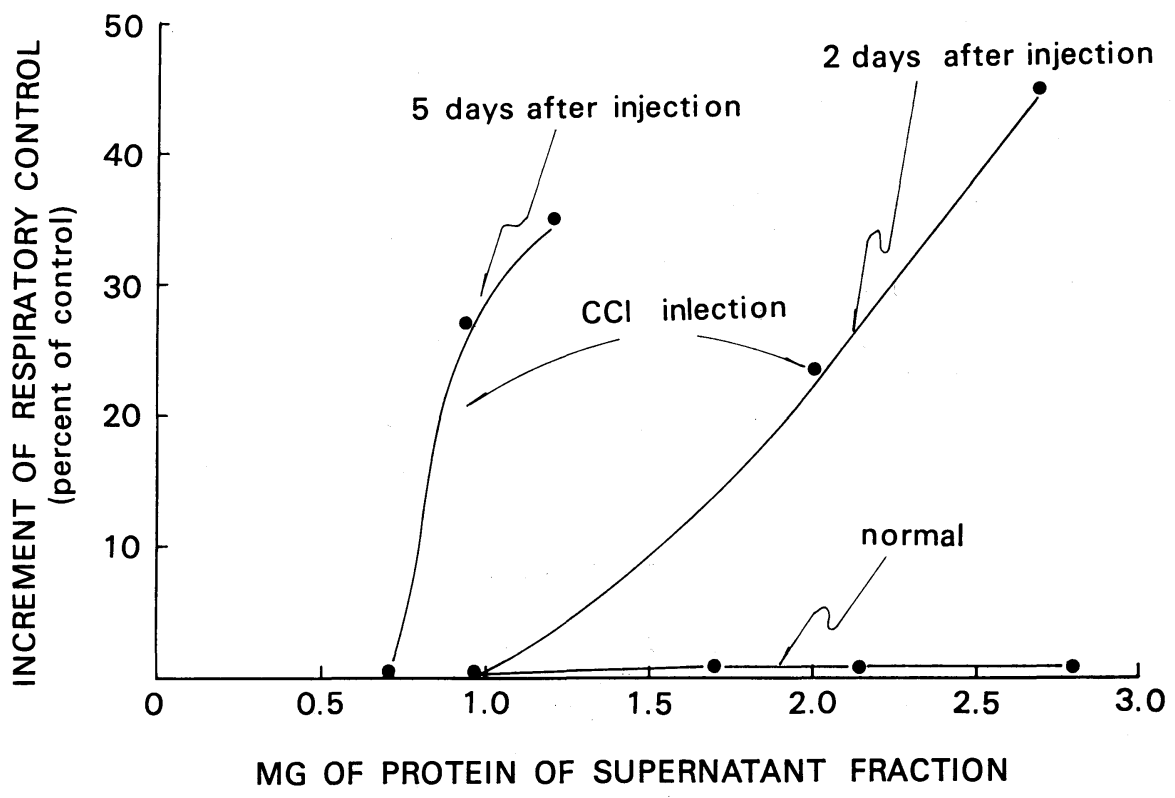

Fig. 2. The effect of the supernatant fraction ( $S$ fraction: $105,000 \mathrm{~g} \times 60 \mathrm{~min}$ ) on the respiratory control of normal rat liver mitochondria.

The respiratory control index of normal rat liver mitochondria was $5.60 \pm 0.04$ and the concentration of mitochondrial protein was $2.0 \mathrm{mg} / \mathrm{ml}$.

injection was more effective than that prepared 2 days after the injection. In other words, the stimulatory activity per milligram of supernatant protein was higher at 5 days than at 2 days.

\section{DISCUSSION}

The data presented above show that the microsomal fraction from the livers of rats poisoned with $\mathrm{CCl}_{4}$ has powerful uncoupling activity. The supernatant fraction $(105,000 \mathrm{~g} \times 60 \mathrm{~min})$ from livers of the poisoned rats antagonized the uncoupling activity of the microsomal fraction and stimulated respiratory control to a degree dependent on the lapse of time after the injection of $\mathrm{CCl}_{4}$.

The uncoupling shown by the supernatant fraction obtained by centrifugation at $10,000 \mathrm{~g} \times$ for $10 \mathrm{~min}$ may not be related to the uncoupling action of fatty acids $^{8}$, because the addition of bovine serum albumin to the reaction mixture did not change the uncoupling activity ${ }^{8}$, and the boiled fraction did not have any uncoupling activity. The mechanism of the uncoupling action of the main microsomal fraction is not known.

It is interesting to note that the supernatant fraction $(105,000 \mathrm{~g} \times 60 \mathrm{~min})$ from the livers of rats poisoned with $\mathrm{CCl}_{4}$ showed significant stimulatory activity 
for respiratory control caused by central depression of state 4 respiration and that this stimulatory activity was dependent on time. The time dependency of the stimulatory activity was related to the time course of changes in the uncoupling activity of the $\mathrm{CCl}_{4}$-poisoned fraction (data in Fig. 1). The specific stimulatory activity increased with increase in time, and the uncoupling activity decreased with increase in time. The effect of the supernatant fraction $(105,000 \mathrm{~g} \times 60 \mathrm{~min})$ on mitochondrial oxidative phosphorylation may be related to the process of recovery from liver injury. The precise mechanism of the stimulatory action of the supernatant fraction is not known. Perhaps, unknown heat-labile factors (as shown in Table 3 ) are present in the supernatant fraction from livers of rats poisoned with $\mathrm{CCl}_{4}$.

\section{REFERENCES}

1) Christie, G.S., and Judah, J.D. (1954). Proc. R. Soc. Ser., B142, 241-257.

2) Reynolds, E.S., Thiers, R.E., and Vallee, B.L. (1962). J. Biol. Chem., 237, 3546-3551.

3) Baccino, F.M., Rita, G.A., and Dianzani, M.U. (1965). Enzymologia, 29, 169-184.

4) Beaufay, H., van Campenhout, E. and de Duve, C. (1959). Biochem. J., 73, 617-623.

5) Recknagel, R.O. and Ghoshal, A.K. (1966). Nature, 210, 1162-1163

6) Utsumi, K. (1963). Acta Med. Okayama, 17, 258-271.

7) Palade, G.E. and Siekevitz, P. (1956). J. Biophys. Biochem. Cytol., 2, 171-200.

8) Lehninger, A.L. and Remmert, L.F. (1959). J. Biol. Chem., 234, 2459-2364 